Article

\title{
Possibilities of Dry and Lubricated Friction Modification Enabled by Different Ultrashort Laser-Based Surface Structuring Methods
}

\author{
Stefan Rung ${ }^{1, *}$, Kevin Bokan ${ }^{1}$, Frederick Kleinwort ${ }^{2}$, Simon Schwarz ${ }^{1}$, Peter Simon ${ }^{2}$, \\ Jan-Hendrik Klein-Wiele ${ }^{2}$, Cemal Esen ${ }^{3}$ and Ralf Hellmann ${ }^{1}$ \\ 1 Applied Laser and Photonics Group, University of Applied Sciences Aschaffenburg, Würzburger Straße 45, \\ 63743 Aschaffenburg, Germany; s130088@th-ab.de (K.B.); simon.schwarz@th-ab.de (S.S.); \\ ralf.hellmann@th-ab.de (R.H.) \\ 2 Laser-Laboratorium Göttingen e.V., Hans-Adolf-Krebs-Weg 1, 37077 Göttingen, Germany; \\ frederick.kleinwort@llg-ev.de (F.K.); peter.simon@llg-ev.de (P.S.); jan-hendrik.klein-wiele@llg-ev.de (J.-H.K.-W.) \\ 3 Applied Laser Technologies, Ruhr-Universität Bochum, Universitätsstraße 150, 44801 Bochum, Germany; \\ esen@lat.rub.de \\ * Correspondence: stefan.rung@th-ab.de; Tel.: +49-6022-81-3694
}

Received: 16 April 2019; Accepted: 13 May 2019; Published: 17 May 2019

\begin{abstract}
In this contribution we report on the possibilities of dry and lubricated friction modification introduced by different laser surface texturing methods. We compare the potential of Laser-Induced Periodic Surface Structures and Laser Beam Interference Ablation on 100Cr6 steel in a linear reciprocating ball-on-disc configuration using 100Cr6 steel and tungsten carbide balls with load forces between $50 \mathrm{mN}$ and $1000 \mathrm{mN}$. For dry friction, we find a possibility to reduce the coefficient of friction and we observe a pronounced direction dependency for surfaces fabricated by Laser Beam Interference Ablation. Furthermore, Laser-Induced Periodic Surface Structures result in a load-dependent friction reduction for lubricated linear reciprocating movements. This work helps to identify the modification behaviour of laser generated micro structures with feature sizes of approximately $1 \mu \mathrm{m}$ and reveals new possibilities for surface engineering
\end{abstract}

Keywords: laser-induced periodic surface structures; laser beam interference ablation; dry friction; lubricated friction; laser surface texturing; smart surfaces

\section{Introduction}

Laser surface texturing enables a precise and reliable method to modify surface properties and provides new ways for the design and fabrication of novel surface functionality towards smart surfaces. In this wide field of surface engineering, the controllable modification of friction and wear is of high interest. A recent study reveals that about $23 \%$ of the world's energy consumption and $8120 \mathrm{Mt} /$ year of $\mathrm{CO}_{2}$ emission are caused by these tribological effects, in turn posing the necessity for wear and friction control [1]. While laser-based surface functionalization has already been intensively studied during the last decade, femtosecond laser technology has recently expedited surface structuring on different length scales to advance tribological properties [2-7]. In terms of laser surface texturing, different methods are available to modify the friction behaviour. On the one hand, regular ablation processes using short (pulse duration $\tau>10 \mathrm{ps}$ ) and ultrashort (pulse duration $\tau<10 \mathrm{ps}$ ) laser pulses are capable of generating meso- to micro-structures with spatial feature size limitation of the applied laser spot size, typically several tens of micrometers. On the other hand, advanced processing techniques can fabricate surface texturing patterns with feature sizes magnitudes below the applied laser spot size. Out of this research field, we use Laser-Induced Periodic Surface Structures (LIPSS) [8] and Laser 
Beam Interference Ablation (LBIA) [9] to fabricate periodic linear patterns on solid surfaces with feature sizes of approx. $1 \mu \mathrm{m}$. The general difference between LIPSS and LBIA is their origin and the respective profile depth. While LBIA structures are generated by a special interferometer-based optical setup, LIPSS occur in a self organizing process based on the interference of the laser irradiation and Surface Plasmon Polaritons (SPP) [10]. Ultrashort laser-based periodic surface structures can be generated on all kind of solid materials [11-13]. Both laser-induced surface morphologies, LIPSS and LBIA, can be generated in a single-step process and provide multiple possibilities to modify different surfaces properties. Possible applications of this laser surface texturing methods involve colorization due to diffraction at the periodic structures [14,15], modification of surface wetting properties [16,17], influence on surface cell growth [18,19], and friction management [20-22]. The friction properties of surfaces depend not only on the specific material and several properties of the sliding surface itself, but also on the properties of the counter body, the sliding speed, the environmental conditions, and the nature of any lubricant. Therefore, it is obvious that numerous experimental studies are needed to get fully acquainted with the effects of laser generated periodic surface structures on such tribological properties.

With growing possibilities of flexible methods for laser-based surface functionalization, the question arises, which method leads to the required effects in the field of surface engineering. A line-wise laser surface texturing can be achieved by both methods, LBIA and LIPSS, and they both have the potential to modify friction behaviour. In different tribological test scenarios, LIPSS fabricated surfaces with features in the range of $1 \mu \mathrm{m}$ and below have shown that it is either possible to increase [23] or to decrease [24] the coefficient of friction (COF). While Gachot et al. [20] report a friction reduction after applying LBIA structures on $100 \mathrm{Cr} 6$ while performing a dry linear reciprocating ball-on-disc test, Kasem et al. [25] identify a friction increase on LBIA structures on SAE 1035 steel in a lubricated linear sliding test. Beside the structural modification, the laser-based surface temperature increase, caused by the laser beam absorption, can influence the chemical properties and thus lead to a modification of sliding friction. The important role of the surface chemistry is supported by the studies of Gachot et al. [26] for LBIA and Bonse et al. [7] for LIPSS.

To the best of our knowledge, a direct comparison of the tribological modification behaviour of different laser generated micro structures of approx. $1 \mu \mathrm{m}$ is not investigated yet. Thus, we use both laser surface texturing methods and demonstrate the possibilities of friction modification and show which method results in which friction behaviour.

\section{Materials and Methods}

\subsection{Laser Surface Texturing}

To compare the different laser surface texturing methods, the structures were applied on a chrome steel (100Cr6) substrate with a thickness of $6.6 \mathrm{~mm}$. Before the laser modification is carried out, the base plate was prepared by grinding and polishing with a multi directional polishing using several abrasive grits and afterwards polished with suspensions down to a grain size of $1 \mu \mathrm{m}$ to achieve a reference surface with a roughness of $R_{a}=14 \mathrm{~nm}$.

\subsubsection{LSFL}

Generally, LIPSS are categorized into 3 groups, namely low spatial frequency LIPSS (LSFL), high spatial frequency LIPSS (HSFL), and cone-like protrusions (CLP) [8]. In this study, we use LSFL to alter tribological properties. These structures appear upon laser irradiation with linear polarized light. The origin of LSFL is commonly explained by an interference effect of the incident laser light and a surface electro-magnetic wave generated by a laser-induced surface plasmon polarition (SPP) [8]. Due to this origin, LSFL occur with a spatial periodicity in the range of the used laser wavelength and an orientation perpendicular to the polarization of the laser light. Several research groups have shown that LSFL properties like spatial period, orientation, and homogeneity can also be controlled by 
the applied laser fluence [27,28], pulse to pulse overlap [29], and initial surface roughness of the solid material [30]. For laser surface processing, we used a micro-machining station (MM200 USP, Optec, Frameries, Belgium) equipped with an ultrashort pulsed laser (Pharos 10-600-PP, Light Conversion, Vilnius, Lithuania) having a pulse duration of $220 \mathrm{fs}(\mathrm{FWHM})$ at a repetition rate of $300 \mathrm{kHz}$. For the generation of the micro- and nano-structures, the fundamental emission wavelength of $1030 \mathrm{~nm}$ was utilized. Figure 1a shows the experimental setup for the surface treatment. The energy of the laser was adjusted by an external attenuator based on a rotating wave plate and a polarizer. Using a half wave plate in front of the focusing unit, the linear polarization of the laser beam was rotated orthogonal to the scanning direction. A galvo scanner (RTA AR800, Newson, Dendermonde, Belgium) was used in combination with a telecentric lens $(\mathrm{f}=100 \mathrm{~mm})$ to focus the beam onto the sample with a spot diameter of $38 \mu \mathrm{m}\left(1 / \mathrm{e}^{2}\right)$.

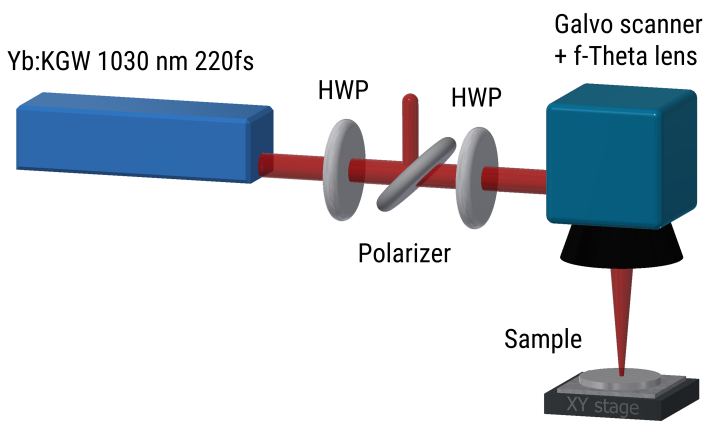

(a) Lasersetup LSFL

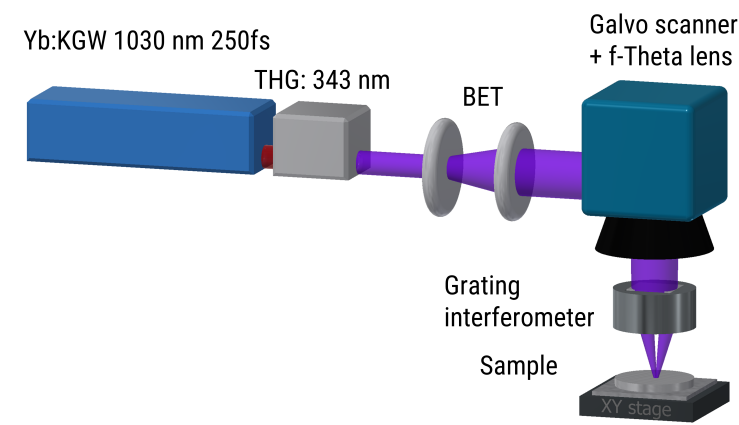

(b) Lasersetup LBIA

Figure 1. Methods for laser surface structuring (a) low spatial frequency LIPSS (laser-induced periodic surface structures, LSFL) setup (b) laser beam interference ablation (LBIA) setup.

\subsubsection{LBIA}

Beside the LSFL process, the test disc was structered with high definition periodic line gratings of a single orientation across the whole disc. For the fabrication of these surface structures, laser beam interference ablation (LBIA) was used as shown in Figure 1b, applying a special interferometer-based technique developed at LLG. In this approach, the key component is a so-called grating interferometer $[9,31]$, which creates a well-defined, high quality interference pattern, projected onto the sample surface. This interferometer consists of two transmission phase gratings made of fused silica with their grating lines lined up parallel to each other. In the present experiment, the resulting period of the linear grating-like structures projected onto the sample surface was $1.5 \mu \mathrm{m}$. A fast scanning system (intelliSCAN $\mathrm{de}_{\mathrm{d}} 14$, SCANLAB GmbH, Puchheim, Germany) with a focusing optic is applied to ablate arbitrary patterns on the sample, while allowing full coverage of the entire processed area with a highly deterministic periodic structure. The modulation depth of the resulting relief structure can be varied within a wide range by adjusting the laser energy and the scanning speed. In the present study, the modulation depth was adjusted to approx. $1.6 \mu \mathrm{m}$ on the surface of the test discs, in order to achieve an aspect ratio of roughly 1:1. The Yb:KGW femtosecond laser source (Pharos 20-1000-PP, Light Conversion, Vilnius, Lithuania) used for the ablation process provides pulses at $300 \mathrm{kHz}$ with a duration of $250 \mathrm{fs}$ at a wavelength of $1030 \mathrm{~nm}$. For the presented investigation the laser system was equipped with a third harmonics module which converted the wavelength to $343 \mathrm{~nm}$. Those ultrashort laser pulses are focused to approx. $20 \mu \mathrm{m}$ and scanned across the sample area. 


\subsection{Surface Analysis}

The generated surface structures were analyzed using atomic force microscopy (XE-150, Park Systems, Suwon, Korea) and scanning electron microscopy (EVO MA10,Carl Zeiss Microscopy GmbH, Jena, Germany). The AFM measurements were used to obtain the 3D surface topology of the different structures in order to determine the depth of the structures. The AFM was operated in non-contact mode using a cantilever with high aspect ratio $(>5: 1)$ silicon tip (NANOSENSORS AR5-NCHR, NanoWorld AG, Neuchatel, Switzerland). Images with $512 \times 512$ pixels were recorded at a scan rate of 0.2 lines per second and a scan size of $10 \times 10 \mu \mathrm{m}$. The SEM images with $1024 \times 768$ pixels were taken at a high voltage of $18-20 \mathrm{kV}$, a filament current of 2.39-2.44 A, and a probe current of 3-20 pA. The working distance was $5-8 \mathrm{~mm}$ and the minimum pixel size $5.86 \mathrm{~nm}$.

\subsection{Tribological Analysis}

The measurement of the COF was performed in a ball-on-disc (BoD) setup. We used a universal mechanical tester (UMT TriboLab, Bruker Corporation, Billerica, MA, USA) to perform the tribological evaluation. The system is equipped with a linear drive allowing linear reciprocating translation and a second drive unit to apply a specific load of the ball on the base plate. The used force sensor allows measuring the load FL and the lateral force FX up to $5 \mathrm{~N}$. The resulting COF is calculated by FX/FL. We measured the friction behaviour between the $100 \mathrm{Cr} 6$ steel substrate and either tribometer balls of chrome steel (100Cr6) or tungsten carbide, both with a diameter of $6.3 \mathrm{~mm}$. The resulting wear on the substrate is captured using laser scanning microscopy (VK-X200, KEYENCE DEUTSCHLAND $\mathrm{GmbH}$, Neu-Isenburg, Germany). Therefore, the track width (point-to point) of the wear tracks on the substrate is measured by a threefold rating. Beside the dry friction test, the COF is measured in a lubricated environment by a thin film of engine oil (5W40).

Due to the elastic deformation of the $100 \mathrm{Cr} 6$ steel and tungsten carbide balls, different contact areas appear. Using a Hertzian deformation model of a sphere in contact with a flat sample, the diameter of the contact area is calculated in Table 1.

Table 1. Diameter of contact areas in the specific ball-on-disc configurations.

\begin{tabular}{cccccc}
\hline \multirow{2}{*}{ Tribometer Ball } & $\mathbf{5 0}$ & $\mathbf{1 0 0}$ & $\mathbf{2 0 0}$ & $\mathbf{5 0 0}$ & $\mathbf{1 0 0 0}$ \\
\hline 100Cr6 steel & $20.2 \mu \mathrm{m}$ & $25.6 \mu \mathrm{m}$ & $32.0 \mu \mathrm{m}$ & $43.4 \mu \mathrm{m}$ & $54.7 \mu \mathrm{m}$ \\
Tungsten carbide & $17.8 \mu \mathrm{m}$ & $22.4 \mu \mathrm{m}$ & $28.3 \mu \mathrm{m}$ & $38.4 \mu \mathrm{m}$ & $48.3 \mu \mathrm{m}$ \\
\hline
\end{tabular}

An overview of the applied tribologcial test conditions is given in Table 2 for both sliding regimes, dry and under lubrication. Due to the decreased wear generation using lubrication, higher load forces and numbers of test cycles are possible.

Table 2. Summarized test conditions of tribological evaluation.

\begin{tabular}{cccccccc}
\hline Sliding Regime & Test Methode & Substrate & Tribometer Ball & Load Force & Velocity & Cycles & Lubricant \\
\hline \multirow{2}{*}{ dry } & Ball-on-disc & \multirow{2}{*}{$100 \mathrm{Cr} 6$} & $\begin{array}{c}100 \mathrm{Cr} 6 \\
\text { tungsten carbide }\end{array}$ & $\begin{array}{c}50 \mathrm{mN} \\
200 \mathrm{mN}\end{array}$ & $4 \mathrm{~mm} / \mathrm{s}$ & 500 & - \\
\hline \multirow{2}{*}{ lubrication } & Ball-on-disc & \multirow{2}{*}{$100 \mathrm{Cr} 6$} & $\begin{array}{c}100 \mathrm{Cr} 6 \\
\text { tungsten carbide }\end{array}$ & $\begin{array}{c}100 \mathrm{mN} \\
500 \mathrm{mN} \\
1000 \mathrm{mN}\end{array}$ & $4 \mathrm{~mm} / \mathrm{s}$ & 1000 & $5 W 40$ \\
\hline
\end{tabular}




\section{Results and Discussion}

\subsection{Laser Surface Texturing}

In the first step, the required laser parameters for continuous surface texturing on 100Cr6 steel are determined. For the LSFL process, the laser fluence and the pulse overlap are optimized to generate a homogeneous LSFL-covered surface. Figure 2a shows the SEM image were the fluence is set to $0.5 \mathrm{~J} / \mathrm{cm}^{2}$ and the pulse to pulse overlap for subsequent laser pulses and scanning lines is $80 \%$. The use of the laser wavelength of $1030 \mathrm{~nm}$ and a linear polarization of the laser light results in a linear pattern with an average spatial periodicity of $\approx 900 \mathrm{~nm}$. Due to the slightly smaller spatial period with respect to the laser wavelength and the perpendicular appearance of the structures, these LIPSS are identified as LSFL. The periodic structures show a uniform periodicity and a straight vertical course. The topographical shape is shown in Figure $2 b$ by a AFM measurement. The height profile shows a homogeneous modulation depth of $(201 \pm 32) \mathrm{nm}$.

For the LBIA process the laser parameters and the scanning overlapp of the focused beam were adjusted to produce lines at a depth of approx. 1.6 to $1.7 \mu \mathrm{m}$. Due to the projection of lines of the grating interferometer onto the sample surface, the resulting surface structures are highly regular with a strict spatial periodicity of $1.5 \mu \mathrm{m}$. The resulting images of the SEM mesurements as well as the measured structural depth from AFM measurement is shown in Figure 2c,d.

The comparision between the LSFL and LBIA structures in Figure 2 shows that the LBIA structures show a higher uniformity and a much more pronounced orientation of the lines. The LSFL structures occur with a 0.6 times smaller spatial periodicity, while the modulation depth of the LBIA structures was about 8 times larger.

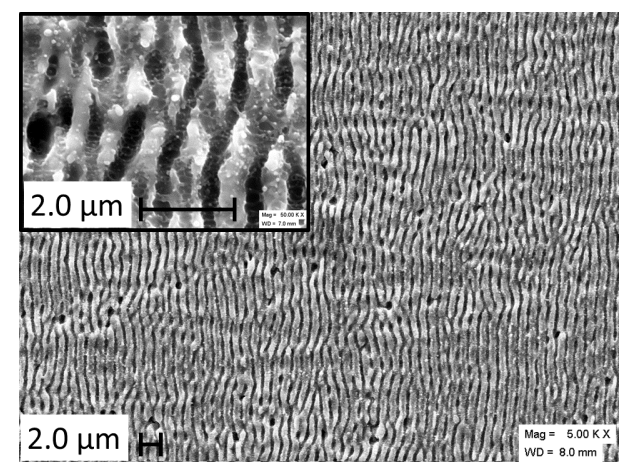

(a) LSFL SEM

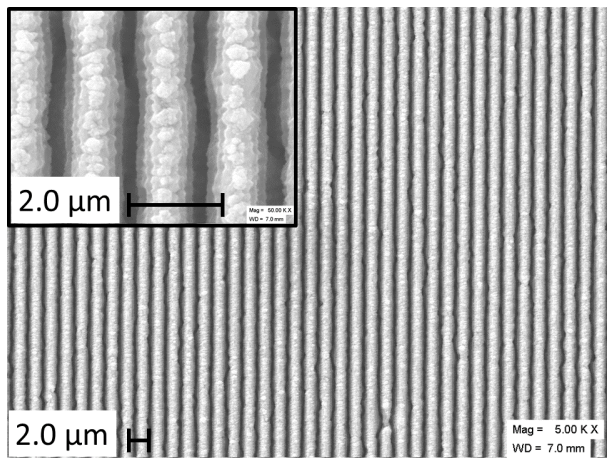

(c) LBIA SEM

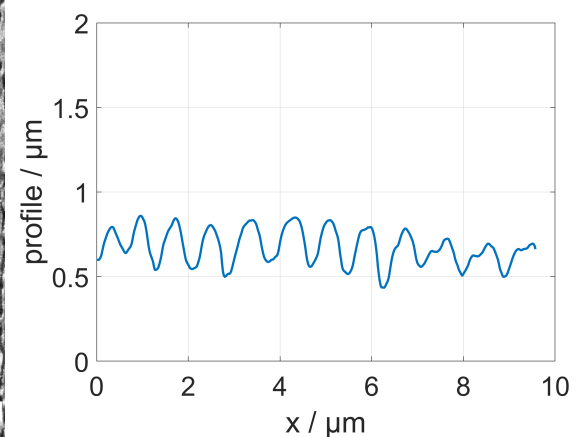

(b) LSFL AFM

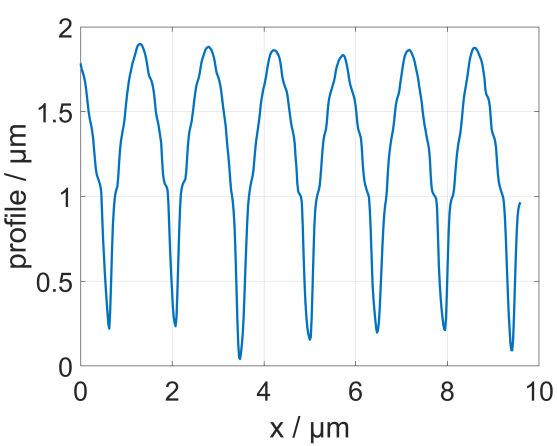

(d) LBIA AFM

Figure 2. Laser-based surface modification using the LSFL and LBIA method. SEM image of LSFL (a) reveals a mostly vertical orientation of the structes and the corosponding AFM profile (b) shows the height profile. Structures fabricated by LBIA show a high homogeneity in the SEM image (c) and the AFM profile (d). 


\subsection{Friction Measurement}

In the following diagrams (Figures 3 and 5-7), the resulting COF is shown for the reference surface (black solid curve), the LBIA-structured surfaces (red curves) and the LSFL-covered surfaces (blue curves). Furthermore, the relation between the periodic surface structures and the sliding direction is indicated by the line style. For a sliding direction along the periodic grooves, dotted lines and the index " -0 " are used. Dashed lines represent a perpendicular sliding movement which is also indicated by the added index "-90". The presented COF values are calcuated by the average of $50 \mathrm{~s}$ of steady measurement of the applied force and the induced lateral force. The shown error bars in Figures 3 and 5-7 represent the deviation of the calculated COF for a time range of $50 \mathrm{~s}$.

\subsubsection{Dry Test $100 \mathrm{Cr} 6$ on $100 \mathrm{Cr} 6$}

Figure 3 shows the results of the tribological linear reciprocating ball-on-disc evaluation using a 100Cr6 disc and a 100Cr6 triboball for $50 \mathrm{mN}$ and $200 \mathrm{mN}$ load force. The oscillating sliding test is performed for $500 \mathrm{~s}$ with a stroke of $2 \mathrm{~mm}$ and a frequency of $1 \mathrm{~Hz}$ which corresponds a total track distance of $2000 \mathrm{~mm}$. On the reference surface, the COF starts at values below 0.2 and rises slightly with ongoing runtime. After $300 \mathrm{~s}$, the COF rises strongly and approaches a steady state after $450 \mathrm{~s}$ with a COF of 0.8 . This COF incline can be described by a damage of the natural superficial oxide layer on the surface [32]. With increasing load force, the COF incline starts already within the first $50 \mathrm{~s}$ and after a total run time of $150 \mathrm{~s}$, the steady state is nearly reached at a COF of approx. 0.9-1. Surfaces covered by LSFL reveal a comparable high COF directly at the beginning of the linear reciprocating movement. For the movement parallel to the LSFL orientation, the COF starts with a value of 0.65 and increases with time to a value of approx. 0.93. The perpendicular movement on LSFL show higher values for the COF over the entire test duration, starting at 0.81 and with a steady state value of 1 . Contrary to the LSFL-covered surface, the LBIA structures introduce only a small COF increase at the beginning of the tribological test. For a perpendicular movement, the COF starts with 0.3 and 0.5 for $50 \mathrm{mN}$ and $200 \mathrm{mN}$ respectively. The break-in effect, which is defined as the initial COF modification by ongoing test duration, is visible for both load forces: For $50 \mathrm{mN}$ the steady state is reached after $400 \mathrm{~s}$ and for $200 \mathrm{mN}$ after $250 \mathrm{~s}$. While LSFL-0, LSFL-90, and LBIA-90 result in a COF increase over the entire linear reciprocating ball-on-disc evaluation for both load forces, LBIA structures combined with a parallel movement (LBIA-0) result in a stable COF value at approx. 0.2 for both $50 \mathrm{mN}$ and $200 \mathrm{mN}$.

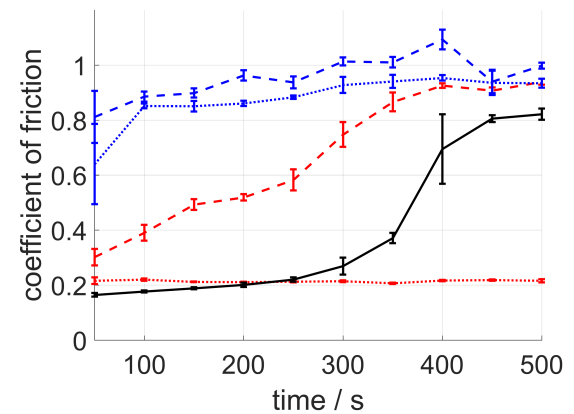

(a) Load force: $50 \mathrm{mN}$

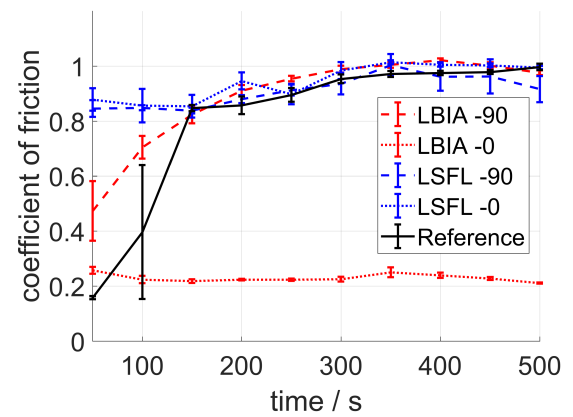

(b) Load Force: $200 \mathrm{mN}$

Figure 3. Temporal evolvement of the coefficient of friction using $100 \mathrm{Cr} 6$ triboball without lubrication for a load force of $50 \mathrm{mN}$ (a) and $200 \mathrm{mN}$ (b).

The differences of the coefficient of friction for LSFL- and LBIA-covered surfaces are also visible in the microscopy image after the linear reciprocating ball-on-disc evaluation. The high COF value for laser surface texturing using LSFL implies a strong interaction between the disc and the triboball. Figure $4 \mathrm{a}$ shows the borderline between the initial LSFL and the friction affected area using a parallel movement and a load force of $50 \mathrm{mN}$. In the sliding track, LSFL vanished completely and big artefacts caused by a strong material adhesion and galling [33] are visible. As indicated by the small COF in 
Figure $3 \mathrm{a}$, the wear on the LBIA surface after the parallel movement in Figure $4 \mathrm{~b}$ is less pronounced. The wear track is visible but the laser surface texturing is still present. Along the complete stroke, no artefacts of material adhesion and galling are visible.

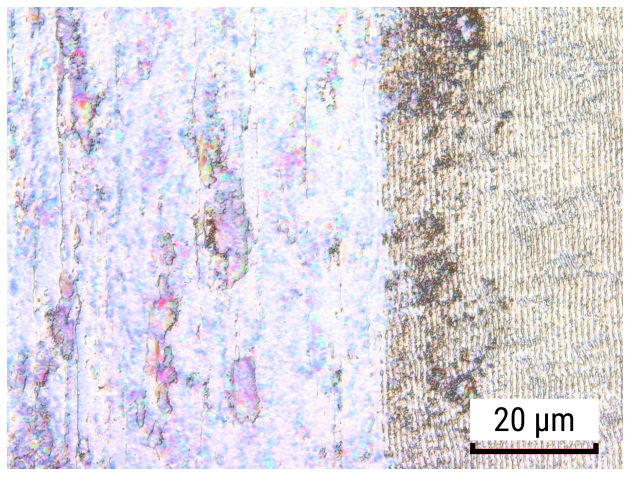

(a) Wear track (left) on LSFL surface

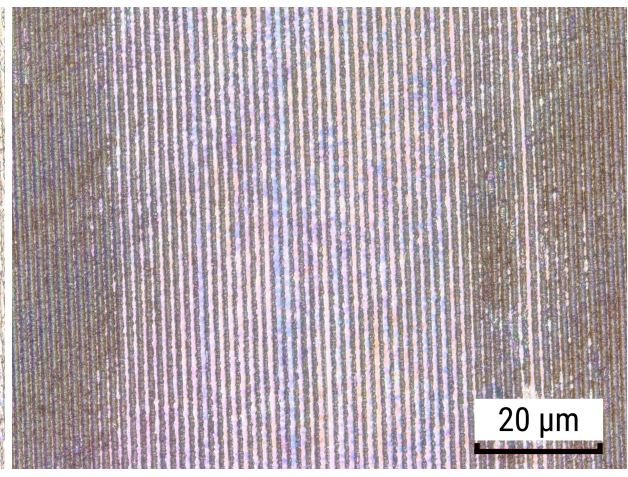

(b) Wear track on LBIA surface

Figure 4. Wear track after dry linear reciprocating evaluation with a load force of $50 \mathrm{mN}$ and a duration of 500 s on LSFL-0 (a) and LBIA-0 (b) covered surfaces.

\subsubsection{Dry Test Tungsten Carbide on 100Cr6}

The results of the tribological linear reciprocating ball-on-disc evaluation using a 100Cr6 disc and a tungsten carbide triboball for $50 \mathrm{mN}$ and $200 \mathrm{mN}$ load force are shown in Figure 5 . The general comparison to the pairing $100 \mathrm{Cr} 6 / 100 \mathrm{Cr} 6$ shows that the coefficient of friction is lower for all tested surfaces. On the polished reference surface, the coefficient of friction is 0.18 in the beginning and rises slightly up to 0.25 for a load force of $50 \mathrm{mN}$. With increasing load (Figure $5 b$ ), the COF increases to values of 0.55 at the end of the evaluation time of $500 \mathrm{~s}$. The LSFL-structured surfaces lead to a COF increase over the entire evaluation time. For parallel and perpendicular movements, the COF starts at 0.45 and stays nearly constant for parallel sliding direction. The COF for the perpendicular movement on LSFL is higher (c.f. dry test $100 \mathrm{Cr} 6 / 100 \mathrm{Cr}$ ) and rises to a steady state at 0.5 . This behaviour also appears for the higher load force of $200 \mathrm{mN}$. The COF for LSFL-0 and LSFL-90 is initially 0.57 and increases to 0.6 for a parallel movement and to 0.68 for a perpendicular sliding direction. The LBIA surface introduce a small COF increase at the beginning of the test for both test loads. Using a perpendicular movement, the COF shows a time-based increase and runs from 0.24 to 0.3 for $50 \mathrm{mN}$ and from 0.27 to 0.41 for $200 \mathrm{mN}$. Contrary to this behaviour, the parallel movement on the LBIA surface reveals a slight COF decrease with ongoing evaluation time. For $50 \mathrm{mN}$ the COF decreases from 0.21 to 0.19 . Using a load force of $200 \mathrm{mN}$, the COF reduces from 0.19 to 0.16 .

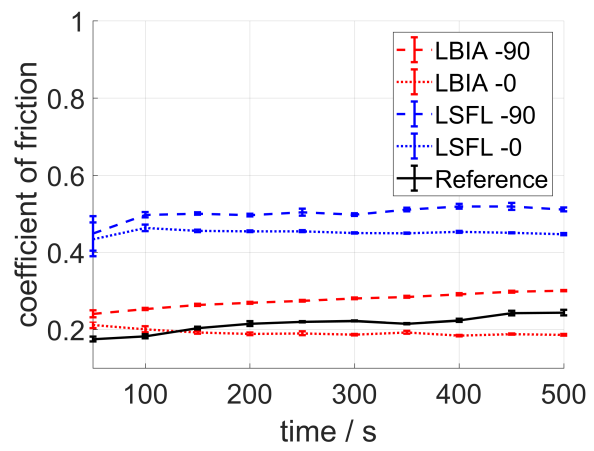

(a) Load force: $50 \mathrm{mN}$

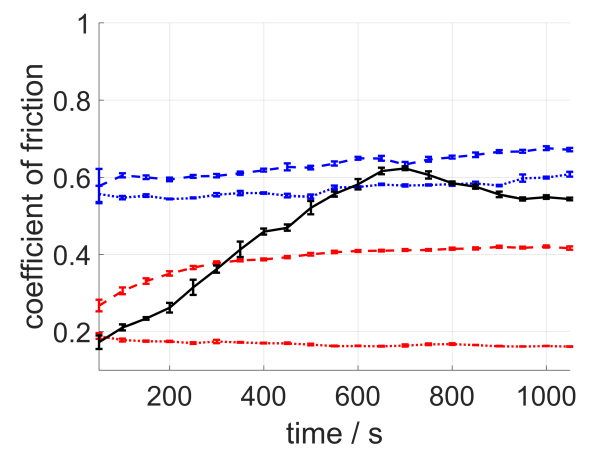

(b) Load force: $200 \mathrm{mN}$

Figure 5. Temporal evolvement of the coefficient of friction using tungsten carbide triboball without lubrication for a load force of $50 \mathrm{mN}$ (a) and $200 \mathrm{mN}$ (b). 


\subsubsection{Lubricated Test $100 \mathrm{Cr} 6$ on $100 \mathrm{Cr} 6$}

In Figure 6, the results for the lubricated tribology test using the $100 \mathrm{Cr} 6$ triboball are shown. Due to the lubricated friction and the adjunctive COF and wear decrease, it is possible to increase the maximum applied load to $1000 \mathrm{mN}$ and the test duration to $1000 \mathrm{~s}$. The oscillating sliding test is performed with a stroke of $2 \mathrm{~mm}$ and a frequency of $1 \mathrm{~Hz}$ which corresponds a total track distance of $4000 \mathrm{~mm}$. Figure $6 \mathrm{a}-\mathrm{c}$ shows the coefficient of friction in a $100 \mathrm{Cr} 6 / 100 \mathrm{Cr} 6$ configuration for $100 \mathrm{mN}$, $500 \mathrm{mN}$, and $1000 \mathrm{mN}$ respectively. The COF measurement on the polished reference surface reveals no remarkable influence of the applied load force and is stable at $0.14-0.15$. For all lubricated test configurations, the initial COF changes with ongoing test duration. Contrary to the dry friction evaluation, this observed break-in effect causes a COF reduction after a specific test duration. While the applied load does not effect the COF on the reference surface, both LSFL- and LBIA-structured surfaces reveal a load dependency for the COF. For a test load of $100 \mathrm{mN}$, laser surface structuring in general introduce a COF increase. Figure 6a reveals that the highest friction is measured on the LBIA surface for a parallel movement. Starting with a COF of 0.29, the ongoing COF decrease within the test duration implies that the break-in effect, i.e., the ongoing change of the COF until it reaches a steady state, is not finished after $1000 \mathrm{~s}$. For $100 \mathrm{mN}$, the influence of sliding direction is well pronounced for both LBIA and LSFL surfaces. The initial friction of LBIA-90 is 0.2 and reduces to 0.18 . The COF for LSFL-covered surfaces is smaller; for a perpendicular sliding direction it starts at 0.19 and reduces to 0.16 and for a parallel movement it starts with a COF of 0.17 and decline to 0.15 . With increasing load force, a remarkable effect is observed, the COF reduces on structured surfaces with increasing load force. For $500 \mathrm{mN}$ and $1000 \mathrm{mN}$ the COF for a parallel movement is smaller on both LBIA- and LSFL-covered surfaces. At the end of the observation time, LBIA surfaces still show an increased COF. According to the reference $\mathrm{COF}$, perpendicular sliding direction on LBIA introduces a $12 \%$ increase and parallel movement a 3\% increase. LSFL reveal the potential to decrease the COF. While the perpendicular movement on LSFL introduces a COF reduction of only $1 \%$, the friction reduction for parallel movement is $7 \%$. Figure $6 \mathrm{c}$ shows that increasing the load force to $1000 \mathrm{mN}$ lead to a further friction reduction for parallel movement on LSFL. After the break-in (approx. 200 s), a stable COF reduction of $12 \%$ according to the reference surface can be measured. On the LBIA-structured surface, a small COF increase of $9 \%$ remains for perpendicular movement and $6 \%$ for parallel movement.

Figure $6 \mathrm{~d}$ shows the width of the generated wear track on the disc's surface for the lubricated oscillating sliding test with a applied load of $1000 \mathrm{mN}$. On laser textured surfaces, the wear track width decreases according to the measured COF values, i.e., the highest COF (LBIA-90) leads to the highest wear width and the lowest COF (LSFL-0) leads to the lowest wear track width. The comparison of the magnitude of the wear track width and the contact diameter between the ball and the flat surface shows a pronounced difference. On LBIA-90 the wear track is more than double for a load force of $1000 \mathrm{mN}$ (cf. Table 1). A friction-based temperature rise in the contact zone could lead to elastic-plastic deformation of the involved interfaces [34,35]. It is worthwhile to mention that the similar COF of the reference and the LSFL-90 surface does not result in a similar wear track width. The laser processing generates a thin oxidized passivation layer on the surface [32], which protects the surface against friction-induced damage. 


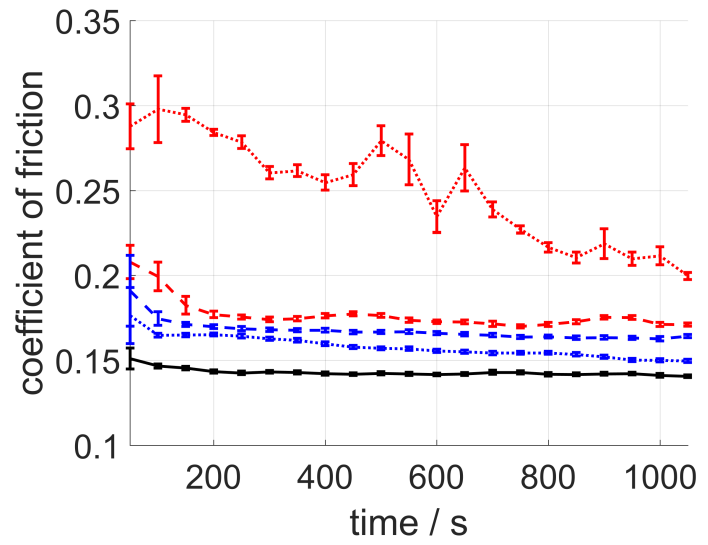

(a) Load force: $100 \mathrm{mN}$

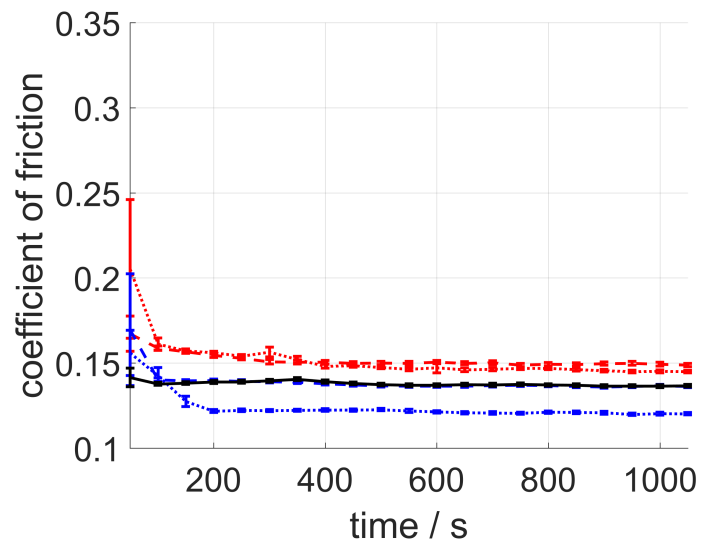

(c) Load force: $1000 \mathrm{mN}$

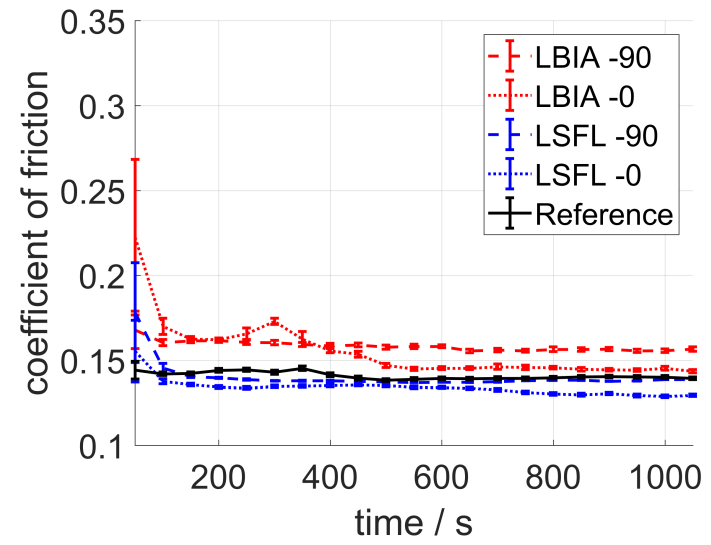

(b) Load force: $500 \mathrm{mN}$

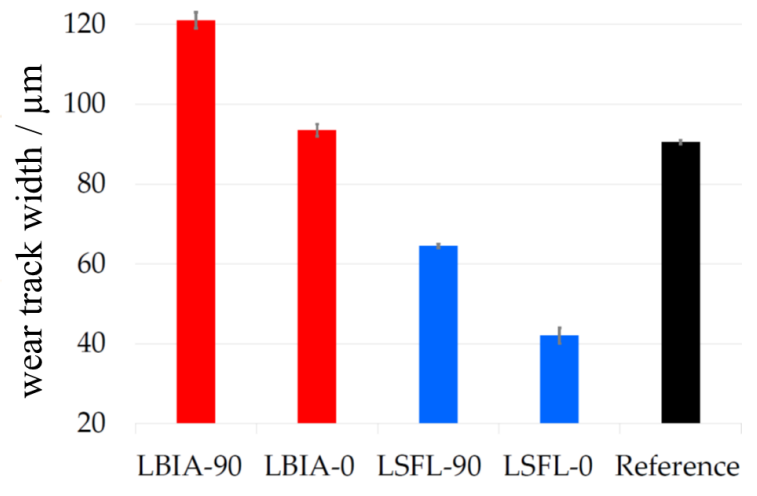

(d) Load force: $1000 \mathrm{mN}$

Figure 6. Tribological evaluation using 100Cr6 triboballs under lubrication. Temporal evolvement of the coefficient for a load force of $100 \mathrm{mN}$ (a), $500 \mathrm{mN}$ (b), and $1000 \mathrm{mN}$ (c). Wear track width on the $100 \mathrm{Cr} 6$ substrate after after $1000 \mathrm{~s}$ test duration using a load force of $1000 \mathrm{mN}$ and 100Cr6 triboballs (d).

\subsubsection{Lubricated Test Tungsten Carbide on 100Cr6}

Figure 7 summarizes the results of the lubricated tribological linear reciprocating ball-on-disc evaluation using a $100 \mathrm{Cr} 6$ disc and a tungsten carbide triboball for $100 \mathrm{mN}, 500 \mathrm{mN}$, and $1000 \mathrm{mN}$ load force. Comparable to the results for lubricated 100Cr6/100Cr6 experiments, the COF of the polished reference surface remains nearly unaffected over the test duration. After a short break-in, the COF is stable between 0.13 and 0.14 . The slight increase of the COF with increasing load force is attributed to the decreasing film thickness of the lubricant between the WC ball and the polished disc surface [36]. For the smallest investigated load of $100 \mathrm{mN}$, all laser textured surfaces introduce a COF larger $(15 \%-20 \%)$ than the reference surface. With increasing load, both laser textured surfaces are characterized by decreasing COF. According to the research of Ben-David et al. [37] or Ma et al. [38], the nonlinear increase of the degree of surface contact with increasing contact pressure of a rough surface is responsible for this effect. Again, the COF of LBIA surfaces stays above the reference surface. LSFL-covered surfaces introduce a COF decrease for an applied load of $500 \mathrm{mN}$ and $1000 \mathrm{mN}$ (c.f. Figure $7 \mathrm{~b}, \mathrm{c}$ ). In both load cases, the direction dependency on LSFL vanishes and a COF reduction of $2 \%$ and $9 \%$ for $500 \mathrm{mN}$ and $1000 \mathrm{mN}$ can be measured, respectively. The COF for LBIA-0 increases with increasing load force. This behaviour is in contrast to all other lasers structures surfaces in this study, and can be expalined by numerical simulations by Zhu and Wang [34,39], who studied the lubricant film thickness between a tribo ball and a surface with linear surface modulations similiar to 
those of the LBIA surface. Sliding along the linear features effects a decrease of the film thickness of the lubricant. On the cusps of the LBIA features, however, little or no lubricant film will be spread. Due to the steady contact during sliding, the lubricant locally leaks out leading to an increased friction. The sliding movement transverse to the line shaped structures (LBIA-90) provides more resitance to the lubricant, causing an increase of the average lubrication film thickness between the ball and the rough surface [34,39].

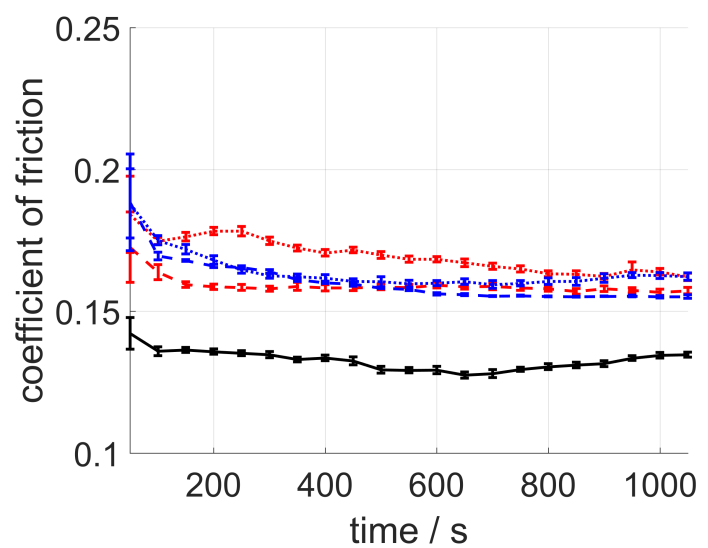

(a) Load force: $100 \mathrm{mN}$

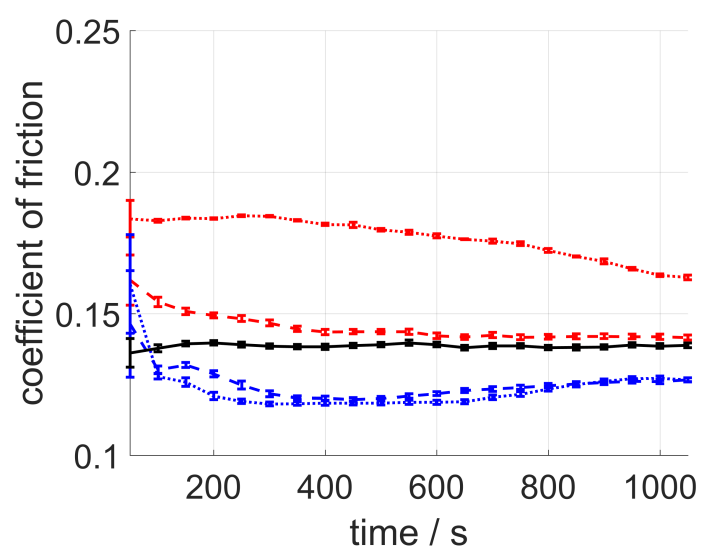

(c) Load force: $1000 \mathrm{mN}$

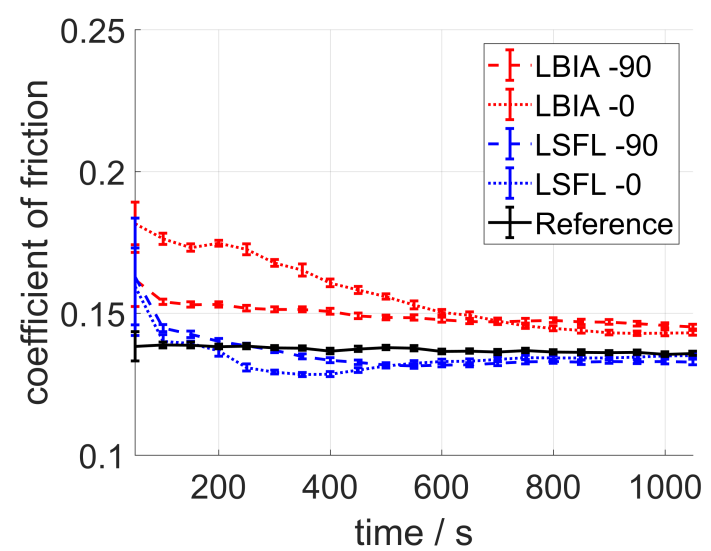

(b) Load force: $500 \mathrm{mN}$

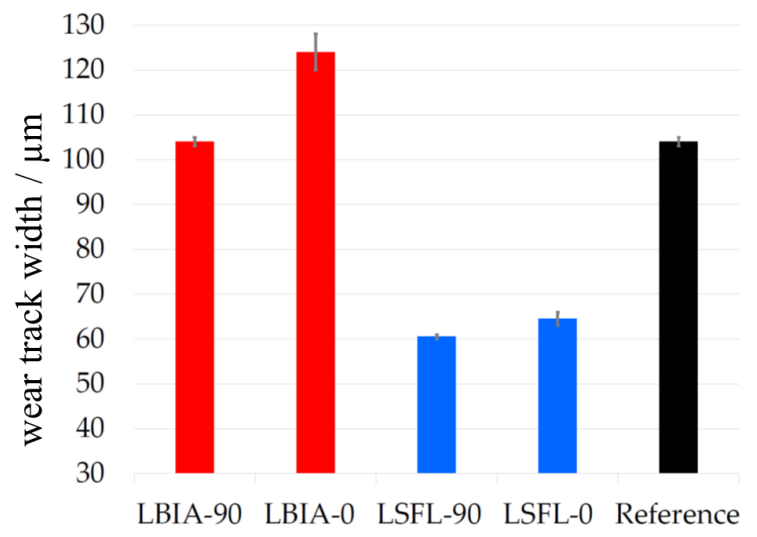

(d) Load force: $1000 \mathrm{mN}$

Figure 7. Tribological evaluation using tungsten carbide triboballs in a lubricated enviroment. Temporal evolution of the coefficient for a load force of $100 \mathrm{mN}(\mathbf{a}), 500 \mathrm{mN}$ (b), and $1000 \mathrm{mN}$ (c). Wear track width on the $100 \mathrm{Cr} 6$ substrate after after $1000 \mathrm{~s}$ test duration using a load force of $1000 \mathrm{mN}$ and tungsten carbide triboballs (d).

The increased and decreased friction caused by LBIA and LSFL also affects the generated wear track width shown in in Figure 7d. As mentioned above, the increased friction on LBIA leads to a temperature increase and thus to an elastic-plastic surface deformation. Figure $7 \mathrm{~d}$ also reveals that the COF reduction on LSFL-covered surfaces leads to a wear reduction on the 100Cr6 disc. According to the reference surface, a reduction wear track width of up to $42 \%$ is possible using LSFL and parallel movement.

\section{Conclusions}

This research work focused on femtosecond laser surface texturing on $100 \mathrm{Cr} 6$ steel using two different methods for the generation of periodic surface structures. Both methods produce a linear pattern on the surface. The LSFL approach fabricates a periodic surface pattern with a spatial period of $\approx 900 \mathrm{~nm}$ and a modulation depth of $\approx 200 \mathrm{~nm}$. Using the LBIA technique, a surface modulation with a 
period of $1.5 \mu \mathrm{m}$ and a depth of $\approx 1.6 \mu \mathrm{m}$ is generated. To compare the potential of friction modification, a tribological linear reciprocating ball-on-disc evaluation is performed using $100 \mathrm{Cr} 6 \mathrm{steel}$ and tungsten carbide (WC) triboballs. The effects of sliding direction and load force are evaluated against a polished reference surface for dry and lubricated conditions. Table 3 summarizes the observed effects with respect to the reference surface, highlighting the potential fields of applications for LBIA and LSFL.

Table 3. Summarized modification possibilities with respect to a polished reference surface indicating no influence (0), increase (+), strong increase (++), decrease (-), and strong decrease (- -) of the coefficient of friction.

\begin{tabular}{ccccccccc}
\hline & \multicolumn{4}{c}{ Dry } & \multicolumn{4}{c}{ Lubricated } \\
Ball & \multicolumn{2}{c}{ LBIA } & \multicolumn{2}{c}{ LSFL } & \multicolumn{3}{c}{ LBIA } & \multicolumn{2}{c}{ LSFL } \\
& $\mathbf{9 0}$ & $\mathbf{0}$ & $\mathbf{9 0}$ & $\mathbf{0}$ & $\mathbf{9 0}$ & $\mathbf{0}$ & $\mathbf{9 0}$ & $\mathbf{0}$ \\
\hline Steel & 0 & -- & + & + & ++ & + & 0 & - \\
WC & - & -- & ++ & + & + & ++ & -- & -- \\
\hline
\end{tabular}

Although LBIA and LSFL generate surface structures with similar periodicity, the overall tribological behaviours are different. For the tribological analysis without lubrication, LSFL causes a COF increase for both the $100 \mathrm{Cr} 6 / 100 \mathrm{Cr} 6$ and $100 \mathrm{Cr} 6 /$ tungsten carbide combinations. The perpendicular movement on LBIA structures generates COF comparable to the reference surface. Parallel sliding direction on LBIA surfaces decreases the friction remarkably for both 100Cr6 and tungsten carbide triboballs. Comparing the lubricated friction behaviour of LSFL and LBIA shows the possibility of COF reduction using LSFL-covered surfaces up to $12 \%$ for $100 \mathrm{Cr} 6 / 100 \mathrm{Cr} 6$ and up to $9 \%$ for $100 \mathrm{Cr} 6 /$ tungsten carbide configuration. An additional benefit of LSFL-covered surfaces in the introduced test scenario is the reduced wear track width. In contrast to the COF reduction introduced by LSFL for lubricated friction, LBIA lead to a COF increase for both 100Cr6 and tungsten carbide triboalls under lubricated test conditions.

Author Contributions: Conceptualization, S.R. and K.B.; Methodology, S.R., K.B., S.S. and J.-H.K.-W.; Software, S.R.; Validation, K.B. and F.K.; Formal analysis, S.R.; Investigation, S.R., K.B. and F.K.; Resources, P.S. and R.H.; Writing-original draft preparation, S.R., K.B. and F.K.; Writing-review and editing, S.R., F.K., P.S., J.-H.K.-W., C.E. and R.H.; Visualization, S.R., K.B. and F.K.; Supervision, P.S., C.E. and R.H.; Funding acquisition, P.S. and R.H.

Funding: This research received no external funding.

Conflicts of Interest: The authors declare no conflict of interest.

\section{References}

1. Holmberg, K.; Erdemir, A. Influence of tribology on global energy consumption, costs and emissions. Friction 2017, 5, 263-284. [CrossRef]

2. Ancona, A.; Carbone, G.; Scaraggi, M.; Mezzapesa, F.P.; Sorgente, D.; Lugarà, P.M. Laser surface micro-texturing to enhance the frictional behavior of lubricated steel. In Proceedings of the SPIE Laser-Based Micro- and Nanoprocessing VIII, San Francisco, CA, USA, 1-6 February 2014; Volume 8968, p. 896806.

3. Scaraggi, M.; Mezzapesa, F.P.; Carbone, G.; Ancona, A.; Tricarico, L. Friction Properties of Lubricated Laser-MicroTextured-Surfaces: An Experimental Study from Boundary- to Hydrodynamic-Lubrication. Tribol. Lett. 2013, 49, 117-125. [CrossRef]

4. Mizuno, A.; Honda, T.; Kikuchi, J.; Iwai, Y.; Yasumaru, N.; Miyazaki, K. Friction Properties of the DLC Film with Periodic Structures in Nano-scale. Tribol. Online 2006, 1, 44-48. [CrossRef]

5. Gnilitskyi, I.; Rotundo, F.; Martini, C.; Pavlov, I.; Ilday, S.; Vovk, E.; Ilday, F.Ö.; Orazi, L. Nano patterning of AISI 316L stainless steel with Nonlinear Laser Lithography: Sliding under dry and oil-lubricated conditions. Tribol. Int. 2016, 99, 67-76. [CrossRef]

6. Eichstädt, J.; Römer, G.; Huis in'tVeld, A.J. Towards Friction Control using laser-induced periodic Surface Structures. Phys. Procedia 2011, 12, 7-15. [CrossRef] 
7. Bonse, J.; Höhm, S.; Koter, R.; Hartelt, M.; Spaltmann, D.; Pentzien, S.; Rosenfeld, A.; Krüger, J. Tribological performance of sub-100-nm femtosecond laser-induced periodic surface structures on titanium. Appl. Surf. Sci. 2016, 374, 190-196. [CrossRef]

8. Bonse, J.; Höhm, S.; Kirner, S.V.; Rosenfeld, A.; Kruger, J. Laser-Induced Periodic Surface Structures-A Scientific Evergreen. IEEE J. Sel. Top. Quantum Electron. 2017, 23, 9000615. [CrossRef]

9. Bekesi, J.; Meinertz, J.; Ihlemann, J.; Simon, P. Fabrication of large-area grating structures through laser ablation. Appl. Phys. A 2008, 93, 27-31. [CrossRef]

10. Bonse, J.; Rosenfeld, A.; Krüger, J. On the role of surface plasmon polaritons in the formation of laser-induced periodic surface structures upon irradiation of silicon by femtosecond-laser pulses. J. Appl. Phys. 2009, 106, 104910. [CrossRef]

11. Nayak, B.K.; Gupta, M.C. Self-organized micro/nano structures in metal surfaces by ultrafast laser irradiation. Opt. Lasers Eng. 2010, 48, 940-949. [CrossRef]

12. Schwarz, S.; Rung, S.; Hellmann, R. Generation of laser-induced periodic surface structures on transparent material-fused silica. Appl. Phys. Lett. 2016, 108, 181607. [CrossRef]

13. Derrien, T.J.Y.; Krüger, J.; Itina, T.E.; Höhm, S.; Rosenfeld, A.; Bonse, J. Rippled area formed by surface plasmon polaritons upon femtosecond laser double-pulse irradiation of silicon: The role of carrier generation and relaxation processes. Appl. Phys. A 2014, 117,77-81. [CrossRef]

14. Vorobyev, A.Y.; Guo, C. Direct femtosecond laser surface nano/microstructuring and its applications. Laser Photonics Rev. 2013, 7, 385-407. [CrossRef]

15. Li, G.; Li, J.; Hu, Y.; Zhang, C.; Li, X.; Chu, J.; Huang, W. Femtosecond laser color marking stainless steel surface with different wavelengths. Appl. Phys. A 2015, 118, 1189-1196. [CrossRef]

16. Rung, S.; Schwarz, S.; Götzendorfer, B.; Esen, C.; Hellmann, R. Time Dependence of Wetting Behavior Upon Applying Hierarchic Nano-Micro Periodic Surface Structures on Brass Using Ultra Short Laser Pulses. Appl. Sci. 2018, 8, 700. [CrossRef]

17. van Ta, D.; Dunn, A.; Wasley, T.J.; Li, J.; Kay, R.W.; Stringer, J.; Smith, P.J.; Esenturk, E.; Connaughton, C.; Shephard, J.D. Laser textured surface gradients. Appl. Surf. Sci. 2016, 371, 583-589.

18. Raimbault, O.; Benayoun, S.; Anselme, K.; Mauclair, C.; Bourgade, T.; Kietzig, A.M.; Girard-Lauriault, P.L.; Valette, S.; Donnet, C. The effects of femtosecond laser-textured Ti-6Al-4V on wettability and cell response. Mater. Sci. Eng. C Mater. Biol. Appl. 2016, 69, 311-320. [CrossRef] [PubMed]

19. Wallat, K.; Dörr, D.; Le Harzic, R.; Stracke, F.; Sauer, D.; Neumeier, M.; Kovtun, A.; Zimmermann, H.; Epple, M. Cellular reactions toward nanostructured silicon surfaces created by laser ablation. J. Laser Appl. 2012, 24, 042016. [CrossRef]

20. Gachot, C.; Rosenkranz, A.; Reinert, L.; Ramos-Moore, E.; Souza, N.; Müser, M.H.; Mücklich, F. Dry Friction Between Laser-Patterned Surfaces: Role of Alignment, Structural Wavelength and Surface Chemistry. Tribol. Lett. 2013, 49, 193-202. [CrossRef]

21. Ancona, A.; Carbone, G.; de Filippis, M.; Volpe, A.; Lugarà, P.M. Femtosecond laser full and partial texturing of steel surfaces to reduce friction in lubricated contact. Adv. Opt. Technol. 2014, 3, 539-547. [CrossRef]

22. Rung, S.; Bokan, K.; Rutsch, K.; Schwarz, S.; Esen, C.; Hellmann, R. Laser Induced Periodic Surface Structures on 100Cr6 Steel for Modification of Friction Demonstrated with Stribeck Test. J. Laser Micro/Nanoeng. 2018, 13, 160-165.

23. Bonse, J.; Kirner, S.V.; Griepentrog, M.; Spaltmann, D.; Krüger, J. Femtosecond Laser Texturing of Surfaces for Tribological Applications. Materials 2018, 11, 801. [CrossRef] [PubMed]

24. Voyer, J.; Klien, S.; Ausserer, F.; Velkavrh, I.; Ristow, A.; Diem, A. Friction Reduction Through Sub-Micro Laser Surface Modifications. Tribologie Schmierungstechnik 2015, 62, 13-18.

25. Kasem, H.; Stav, O.; Grützmacher, P.; Gachot, C. Effect of Low Depth Surface Texturing on Friction Reduction in Lubricated Sliding Contact. Lubricants 2018, 6, 62. [CrossRef]

26. Gachot, C.; Grützmacher, P.; Rosenkranz, A. Laser Surface Texturing of TiAl Multilayer Films-Effects of Microstructure and Topography on Friction and Wear. Lubricants 2018, 6, 36. [CrossRef]

27. Golosov, E.V.; Emel'yanov, V.I.; Ionin, A.A.; Kolobov, Y.R.; Kudryashov, S.I.; Ligachev, A.E.; Novoselov, Y.N.; Seleznev, L.V.; Sinitsyn, D.V. Femtosecond laser writing of subwave one-dimensional quasiperiodic nanostructures on a titanium surface. JETP Lett. 2009, 90, 107-110. [CrossRef] 
28. Okamuro, K.; Hashida, M.; Miyasaka, Y.; Ikuta, Y.; Tokita, S.; Sakabe, S. Laser fluence dependence of periodic grating structures formed on metal surfaces under femtosecond laser pulse irradiation. Phys. Rev. B 2010, 82, 165417. [CrossRef]

29. Bonse, J.; Krüger, J. Pulse number dependence of laser-induced periodic surface structures for femtosecond laser irradiation of silicon. J. Appl. Phys. 2010, 108, 034903. [CrossRef]

30. Preusch, F.; Rung, S.; Hellmann, R. Influence of Polishing Orientation on the Generation of LIPSS on Stainless Steel. J. Laser Micro/Nanoeng. 2016, 11, 137-142. [CrossRef]

31. Bekesi, J.; Simon, P.; Ihlemann, J. Deterministic sub-micron 2D grating structures on steel by UV-fs-laser interference patterning. Appl. Phys. A 2014, 114, 69-73. [CrossRef]

32. Kirner, S.V.; Slachciak, N.; Elert, A.M.; Griepentrog, M.; Fischer, D.; Hertwig, A.; Sahre, M.; Dörfel, I.; Sturm, H.; Pentzien, S.; et al. Tribological performance of titanium samples oxidized by fs-laser radiation, thermal heating, or electrochemical anodization. Appl. Phys. A 2018, 124, 326. [CrossRef]

33. Czichos, H.; Habig, K.H. Tribologie-Handbuch: Tribometrie, Tribomaterialien, Tribotechnik, 4th ed.; Springer Fachmedien Wiesbaden: Wiesbaden, Germany, 2015.

34. Zhu, D.; Wang, J.; Wang, Q.J. On the Stribeck Curves for Lubricated Counterformal Contacts of Rough Surfaces. J. Tribol. 2015, 137, 021501. [CrossRef]

35. Gelinck, E.; Schipper, D.J. Calculation of Stribeck curves for line contacts. Tribol. Int. 2000, 33, $175-181$. [CrossRef]

36. Zhu, D.; Wang, Q.J. On the lambda ratio range of mixed lubrication. Proc. Inst. Mech. Eng. Part J J. Eng. Tribol. 2012, 226, 1010-1022. [CrossRef]

37. Ben-David, O.; Fineberg, J. Static friction coefficient is not a material constant. Phys. Rev. Lett. 2011, 106, 254301. [CrossRef]

38. Ma, X.; de Rooij, M.; Schipper, D. A load dependent friction model for fully plastic contact conditions. Wear 2010, 269, 790-796. [CrossRef]

39. Zhu, D.; Wang, Q.J. Effect of Roughness Orientation on the Elastohydrodynamic Lubrication Film Thickness. J. Tribol. 2013, 135, 031501. [CrossRef]

(C) 2019 by the authors. Licensee MDPI, Basel, Switzerland. This article is an open access article distributed under the terms and conditions of the Creative Commons Attribution (CC BY) license (http:/ / creativecommons.org/licenses/by/4.0/). 